\title{
Variation near complement factor I is associated with risk of advanced AMD
}

\author{
Jesen A Fagerness ${ }^{1,2}$, Julian B Maller ${ }^{1,2,3}$, Benjamin M Neale ${ }^{1,2,4}$, Robyn C Reynolds ${ }^{5}$, \\ Mark J Daly ${ }^{1,2}$ and Johanna M Seddon*,5
}

${ }^{1}$ Center for Human Genetic Research, Massachusetts General Hospital, Boston, MA, USA; ${ }^{2}$ Program in Medical and Population Genetics, Broad Institute of Harvard and MIT, Cambridge, MA, USA; ${ }^{3}$ Department of Statistics, University of Oxford, Oxford, UK; ${ }^{4}$ SGDP Centre, Institute of Psychiatry, King's College London, London, UK; ${ }^{5}$ Ophthalmic Epidemiology and Genetics Service, New England Eye Center, Tufts Medical Center, Boston, MA, USA

A case-control association study for advanced age-related macular degeneration was conducted to explore several regions of interest identified by linkage. This analysis identified a single nucleotide polymorphism just $3^{\prime}$ of complement factor I on chromosome 4 showing significant association $\left(P<10^{-7}\right)$. Sequencing was performed on coding exons in linkage disequilibrium with the detected association. No obvious functional variation was discovered that could be the proximate cause of the association, suggesting a noncoding regulatory mechanism.

European Journal of Human Genetics (2009) 17, 100-104; doi:10.1038/ejhg.2008.140; published online 6 August 2008

Keywords: AMD; macular degeneration; genetic association; complement pathway

\section{Introduction}

The association of age-related macular degeneration (AMD) with variants on chromosome 1 (complement factor $\mathrm{H}(\mathrm{CFH})$ ), chromosome 6 (CFB; $\mathrm{C} 2)$, chromosome 10 (LOC387715/ARMS2), and chromosome 19 (C3) has clearly identified the primary role of the complement pathway in disease pathogenesis, and is consistent with the linkage peaks observed in several whole-genome linkage studies. ${ }^{1-9}$ Follow-up of whole-genome linkage regions with fine-mapping has met with limited success in many other complex diseases. However, the effect sizes of the identified risk variants for AMD have been dramatically larger than most late-onset disease associations. ${ }^{10-12} \mathrm{AMD}$, the leading cause of irreversible blindness in older adults, ${ }^{13}$ has become a model for the genetics of complex disease. In

${ }^{*}$ Correspondence: Dr JM Seddon, Ophthalmic Epidemiology and Genetics Service, New England Eye Center, 800 Washington Street, 450, Tufts Medical Center, Boston, MA 02111, USA.

Tel: + 1617636 9000; Fax: + 1617636 1124;

E-mail: jseddon@tuftsmedicalcenter.org

Received 22 February 2008; revised 25 June 2008; accepted 27 June 2008; published online 6 August 2008 light of these early successes, we selected 1500 single nucleotide polymorphisms (SNPs) using two different criteria: targeting genes in regions under suggestive linkage peaks from a recent meta-analysis ${ }^{1}$ and genes selected from the complement pathway not in these regions.

\section{Materials and methods \\ Sample}

The study population consisted of 2053 unrelated Caucasian individuals 60 years of age or older diagnosed based on ocular examination and fundus photography. There were 1228 cases of both dry and neovascular (wet) advanced AMD and 825 controls. ${ }^{14}$ The mean age was 74 years for controls (54\% women) and 78 years for affected individuals (55\% women). ${ }^{8}$ Informed consent was obtained in writing from all participants, and procedures were approved by the appropriate institutional review boards. This is largely the same sample set with the same phenotyping criteria that we described in detail previously. ${ }^{8,9}$ Importantly, this sample has been previously confirmed to show no inflation of case-control association statistics because of population substructure. $^{8}$ 


\section{SNP selection}

We selected a total of 1500 SNPs in complement pathway genes and across regions of chromosomes $1,2,3,4,6$, and 16 based on the Fisher et al ${ }^{1}$ bin rank of a meta-analysis of previous whole-genome linkage studies. We chose SNPs in and around regions of transcription as described by Wiltshire et al. ${ }^{15}$ However, we built upon the efficiency of this strategy by only selecting SNPs that tag seven or more other SNPs. This SNP selection routine was conducted by using tagger (http://www.broad.mit.edu/mpg/tagger/) and HapMap data from the CEPH population (phase II, http:// www.hapmap.org). We selected SNPs with a minor allele frequency $(\mathrm{MAF})>10 \%$ and with a minimum $r^{2}$ of 0.8 . Within this set of SNPs were nine SNPs in and around the complement factor I (CFI) region. We chose another 20 SNPs in the region to adequately tag the entire region using the same tagging parameters as above. The 29 total SNPs span a 173 kilobase $(\mathrm{kb})$ region and tag 114 out of the 116 HapMap SNPs in the area that have a MAF above 5\%. These 29 tag SNPs provide very good information coverage for the 114 HapMap SNPs having a mean $r^{2}=0.966$.

\section{Genotyping}

The 1500 SNPs were genotyped at the Center for Inherited Disease Research (CIDR) using an Illumina OPA of which 1409 SNPs passed quality control measures as previously outlined. ${ }^{8}$ The follow-up genotyping and sequencing was performed at the Broad and National Center for Research Resources (NCRR) Center for Genotyping and Analysis using the Sequenom MassARRAY system for iPLEX assays and the ABI 3700XL sequencing system, respectively.

\section{Sequencing}

A novel SNP was discovered by sequencing 85 subjects as a subset of our case-control cohort. This SNP has been labeled Broad13981263 and is an A/G SNP, with A being the major allele, and $G$ having an MAF of $7.65 \%$. Broad13981263 is on chromosome 4 just $5^{\prime}$ (113 bp) of CFI's exon 12 according to dbSNP, and is located at the coordinate 110883313 base pairs on chromosome 4 according to NCBI build 36.1 (Table 1). Broad13981263 has an $r^{2}$ of $0.057,0.006$, and 0.003 , respectively with rs13117504, rs10033900, and rs11726949. As our two most associated SNPs are not in high correlation with our novel SNP, nor does it have an MAF that is very close to our associated SNPs, we are fairly certain that Broad13981263 is not the causal SNP driving the association in the region between 110787671 and 110961059 .

\section{Analysis}

All linkage disequilibrium (LD) calculations were performed with Haploview. ${ }^{16}$ We conducted single-locus and two-marker haplotype association analysis using logistic regression tests implemented in PLINK. ${ }^{17,18}$

\section{Liability estimation}

To calculate the percent variance accounted for by any risk alleles, we assume a prevalence of late-stage AMD in this older age group to be $5 \%$ and that liability is normally distributed in the population, with a mean of 0 and a variance of 1 .

\section{Results}

The most significantly associated SNP in the experiment, rs10033900 $\left(P=9.11 \times 10^{-8}\right)$, resides in the chromosome 4 linkage peak region according to Fisher $e a^{1}$ and was very close to genome-wide significance levels as put forth by Dudbridge and Gusnanto and Pe'er et al ${ }^{19,20}$ (Supplementary Table 1 shows the full results of the screen). Several nearby SNPs were also associated with $P<0.0005$, suggesting this association was not because of a sporadic genotyping artifact. This SNP is $2781 \mathrm{bp}$ upstream of the $3^{\prime}$ UTR of CFI.

Given this compelling result, we decided to genotype a much higher density of SNPs in this region. Our originally associated SNP (rs10033900) remained the most highly associated SNP with a $P$-value of $6.46 \times 10^{-8}(\mathrm{OR}=0.7056$ referring to lower-risk $\mathrm{C}$ allele) (Table 2). This SNP showed a

Table 1 New SNP found by sequencing the CFI exonic regions

\begin{tabular}{|c|c|c|c|c|}
\hline SNP name & Chromosome & hg18 & Major allele & Sequence \\
\hline Broad13981263 & 4 & 110883313 & A & 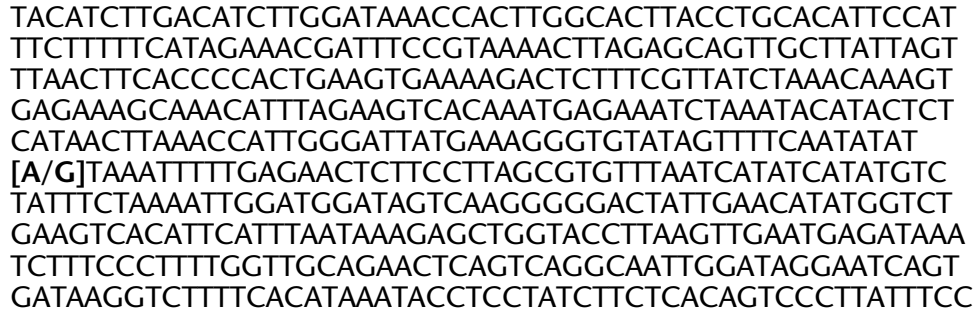 \\
\hline
\end{tabular}

Abbreviations: SNP, single nucleotide polymorphisms; hg18, Human genome build 18; NCBI build 36.1. 
Table 29 SNPs tested across PLA2G12A and CFI on chromosome 4

\begin{tabular}{|c|c|c|c|c|c|c|c|c|c|c|c|}
\hline $\mathrm{CHR}$ & SNP & hg18 & $\begin{array}{c}\text { SNP } \\
\text { spacing }\end{array}$ & $\begin{array}{l}\text { Allele } 1 \\
\text { (A1) }\end{array}$ & $\begin{array}{c}\text { Frequency of } \\
\text { A1 affected } \\
\text { (\%) }\end{array}$ & $\begin{array}{l}\text { Frequency of } \\
\text { A1 unaffected } \\
\text { (\%) }\end{array}$ & $\begin{array}{l}\text { Allele } 2 \\
\quad(A 2)\end{array}$ & CHISQ & P-value & $\begin{array}{l}\text { Odds } \\
\text { ratio }\end{array}$ & $\begin{array}{l}\text { Conditional } \\
\text { rs10033900 }\end{array}$ \\
\hline 4 & rs13101299 & 110787671 & & A & 10.0 & 8.9 & G & 1.40 & 0.237 & 1.138 & 0.123 \\
\hline 4 & rs9990765 & 110788160 & 489 & C & 30.1 & 36.5 & $\mathrm{~T}$ & 18.15 & $2.04 \mathrm{E}-05$ & 0.750 & 0.114 \\
\hline 4 & rs4698774 & 110791792 & 3632 & G & 27.5 & 27.6 & C & 0.00 & 0.953 & 0.996 & 0.782 \\
\hline 4 & rs6830606 & 110793498 & 1706 & C & 9.7 & 8.5 & $\mathrm{~T}$ & 1.74 & 0.187 & 1.158 & 0.843 \\
\hline 4 & rs7690921 ${ }^{a}$ & 110798195 & 4697 & $\mathrm{~T}$ & 35.4 & 29.5 & A & 15.59 & $7.87 \mathrm{E}-05$ & 1.312 & 0.224 \\
\hline 4 & rs17440280 & 110801549 & 3354 & C & 37.5 & 36.8 & $\mathrm{~T}$ & 0.21 & 0.648 & 1.031 & 0.661 \\
\hline 4 & rs4698779 & 110816366 & 14817 & G & 12.9 & 13.9 & C & 0.89 & 0.346 & 0.916 & 0.252 \\
\hline 4 & rs $1800627^{a}$ & 110833107 & 16741 & $\mathrm{~T}$ & 45.8 & 51.4 & $\mathrm{C}$ & 12.53 & $4.01 \mathrm{E}-04$ & 0.798 & 0.747 \\
\hline 4 & rs768063 & 110839905 & 6798 & A & 3.8 & 3.3 & G & 0.89 & 0.345 & 1.180 & 0.318 \\
\hline 4 & rs5030535 & 110841576 & 1671 & G & 34.3 & 40.3 & A & 14.82 & $1.18 \mathrm{E}-04$ & 0.776 & 0.610 \\
\hline 4 & $\operatorname{rs} 2285714^{\mathrm{a}}$ & 110858259 & 16683 & $\mathrm{~T}$ & 46.2 & 38.8 & C & 21.35 & $3.84 \mathrm{E}-06$ & 1.350 & 0.446 \\
\hline 4 & rs2107047 & 110867224 & 8965 & A & 7.4 & 8.2 & G & 0.82 & 0.364 & 0.898 & 0.667 \\
\hline 4 & rs $6854876^{b}$ & 110872889 & 5665 & C & 40.1 & 47.3 & G & 18.86 & $1.41 \mathrm{E}-05$ & 0.747 & 0.118 \\
\hline 4 & rs2346841 b & 110874089 & 1200 & A & 6.0 & 6.4 & G & 0.26 & 0.607 & 0.931 & 0.437 \\
\hline 4 & rs13117504 & 110878305 & 4216 & G & 37.7 & 45.8 & $\mathrm{C}$ & 26.93 & $2.11 \mathrm{E}-07$ & 0.715 & 0.028 \\
\hline 4 & rs10033900 a,b & 110878516 & 211 & C & 46.0 & 54.7 & $\mathrm{~T}$ & 29.22 & $6.46 \mathrm{E}-08$ & 0.706 & NA \\
\hline 4 & rs11726949 & 110884079 & 5563 & $\mathrm{~T}$ & 7.9 & 5.0 & C & 11.96 & $5.44 \mathrm{E}-04$ & 1.627 & 0.007 \\
\hline 4 & rs $6848178^{\mathrm{b}}$ & 110885620 & 1541 & $\mathrm{~T}$ & 42.8 & 46.0 & A & 3.71 & 0.054 & 0.879 & 0.499 \\
\hline 4 & rs6822976 ${ }^{a}$ & 110885741 & 121 & A & 48.4 & 49.0 & G & 0.15 & 0.698 & 0.976 & 0.300 \\
\hline 4 & rs9998151 ${ }^{\mathrm{b}}$ & 110886794 & 1053 & C & 5.2 & 3.7 & $\mathrm{~T}$ & 4.32 & 0.038 & 1.410 & 0.200 \\
\hline 4 & rs4698784 & 110888710 & 1916 & A & 32.6 & 31.3 & $\mathrm{~T}$ & 0.72 & 0.397 & 1.061 & 0.475 \\
\hline 4 & rs11098043 & 110891734 & 3024 & G & 23.8 & 24.9 & A & 0.55 & 0.457 & 0.946 & 0.805 \\
\hline 4 & rs13129180 & 110905862 & 14128 & $\mathrm{~T}$ & 26.3 & 27.2 & A & 0.43 & 0.513 & 0.952 & 0.816 \\
\hline 4 & rs $1000954^{\mathrm{b}}$ & 110929483 & 23621 & A & 28.9 & 30.6 & G & 1.36 & 0.243 & 0.918 & 0.639 \\
\hline 4 & rs $4698788^{a}$ & 110938983 & 9500 & C & 2.8 & 2.7 & $\mathrm{~T}$ & 0.04 & 0.847 & 1.039 & 0.686 \\
\hline 4 & rs $7675460^{b}$ & 110940037 & 1054 & A & 39.1 & 37.6 & C & 0.84 & 0.359 & 1.065 & 0.234 \\
\hline 4 & rs4698792 ${ }^{\mathrm{a}}$ & 110948753 & 8716 & $\mathrm{~T}$ & 29.2 & 30.3 & C & 0.61 & 0.434 & 0.947 & 0.943 \\
\hline 4 & rs1002989 & 110953291 & 4538 & C & 8.7 & 5.9 & $\mathrm{~T}$ & 11.19 & $8.25 \mathrm{E}-04$ & 1.527 & 0.020 \\
\hline 4 & $\mathrm{rs} 4422417^{\mathrm{a}}$ & 110961059 & 7768 & G & 14.1 & 11.9 & A & 3.95 & 0.047 & 1.213 & 0.073 \\
\hline
\end{tabular}

Abbreviations: SNP, single nucleotide polymorphism; hg18, Human genome build 18; NCBI build 36.1; CHISQ, $\chi^{2}$-value of allele 1 frequency differences between cases and controls.

Conditional rs10033900, $P$-value based on conditional logistic regression of SNP.

${ }^{a}$ SNP tested on Sequenom iPLEX at Broad and (NCRR) Center.

${ }^{\mathrm{b}}$ SNP tested on Illumina OPA at CIDR.

Table 3 Two-marker haplotype association results for most significant SNPs in CFI region

\begin{tabular}{|c|c|c|c|c|c|c|c|}
\hline SNPS & Haplotype & $\begin{array}{l}\text { Frequency of } \\
\text { affected (\%) }\end{array}$ & $\begin{array}{l}\text { Frequency of } \\
\text { unaffected (\%) }\end{array}$ & $\begin{array}{l}\text { Degrees of } \\
\text { freedom }\end{array}$ & CHISQ & P-value & Odds ratio \\
\hline rs13117504|rs10033900 & OMNIBUS & NA & NA & 3 & 34.61 & $1.48 \mathrm{E}-07$ & NA \\
\hline rs13117504|rs10033900 & GC & 33.64 & 41.48 & 1 & 25.51 & $4.39 \mathrm{E}-07$ & 0.715 \\
\hline rs13117504|rs10033900 & $\mathrm{CC}$ & 12.39 & 13.25 & 1 & 0.6447 & 0.4220 & 0.926 \\
\hline rs13117504|rs10033900 & GT & 3.90 & 4.35 & 1 & 0.5068 & 0.4765 & 0.891 \\
\hline
\end{tabular}

Abbreviations: CHISQ, $\chi^{2}$-value; NA, Not Applicable (OMNIBUS is a test of all haplotypes) ${ }^{17}$; SNPs, single nucleotide polymorphisms tested as haplotypes.

very high level of genotyping concordance between the Illumina assay and the iPLEX assay designs.

We tested 29 SNPs across this region for association; conditioning on our most associated SNP, rs10033900, and observed no significant independent associations. We did, however, observe modest residual association at two neighboring, highly correlated SNPs (Table 2). This result suggests that rs10033900 may not be the causal variant but may be highly correlated with said variant. Therefore, we applied multimarker haplotype tests in an attempt to refine and isolate the association signal. We tested the twomarker haplotype of the two closest SNPs to rs10033900, both $5^{\prime}$ (rs13117504) and $3^{\prime}$ (rs11726949). The two-marker haplotype between rs13117504 and rs10033900 shows a somewhat stronger association to AMD than either SNP alone with a $P$-value of $1.18 \times 10^{-8}$ (Table 3 ). None of these three SNPs appear to be functional, although rs11726949 is in intron 11 of CFI. We also tested for differences in 
association between the neovascular ('wet') and geographic atrophy ('dry') forms of advanced AMD and found only a $0.2 \%$ difference in MAF (46\%) between the two groups.

We conservatively defined the span of LD that encompassed the SNPs of interest. All other HapMap SNPs in this region are correlated to rs10033900 and rs13117504 with an $r^{2}>0.35$. Multimarker haplotype testing across this region did not show any further association above the levels observed by the two-marker haplotype created between rs13117504 and rs10033900. We then sequenced all of the exons in this region to determine whether an obvious functional variant exists that explains this association. This block of LD spans the last two exonic regions of the $3^{\prime}$ end of CFI and all four exons of phospholipase $\mathrm{A}(2)$ group 12A (PLA2G12A). We found no SNPs in either gene transcript that could statistically explain the association observed at rs10033900. We did find a novel SNP just $5^{\prime}$ of exon 12 in CFI, but this SNP does not appear to be in high $r^{2}$ with our associated SNP or haplotype and is, therefore, not the biological source of association.

We next evaluated the role of epistasis between rs10033900 and rs13117504 and the six variants previously established to be associated with AMD. ${ }^{2-9}$ Specifically, two variants at $\mathrm{CFH}$, two variants at the $\mathrm{CFB} / \mathrm{C} 2$ locus, one at the LOC387715/HTRA1 locus, and one at the C3 locus were established as unequivocally associated to AMD risk in this cohort - the typing and analysis of which was described in Maller et al. ${ }^{8,9}$ Using logistic regression, we observed no statistically significant interaction terms between any pair of these SNPs. Although weak interactions cannot be excluded, this result suggests that despite targeting the same pathway, these variants largely confer risk in an independent, log-additive fashion.

Given the independent action of this new variant, we were able to add it to the multilocus model from Maller et al. ${ }^{9}$ We estimate that this variant accounts for approximately $1 \%$ of the population variance of liability. ${ }^{21}$

\section{Discussion}

We identify one more gene involved in the complement pathway implicated in AMD pathogenesis. Although the complement pathway has been extensively studied, we are only recently learning about its relationship with AMD. The CFI gene spans $63 \mathrm{~kb}$ and contains 13 exons, the first 8 of which encode the heavy chain and the last 5 the light chain, which contains the serine protease domain. ${ }^{22}$ This serine protease domain is responsible for cleaving and inactivating $\mathrm{C} 4 \mathrm{~b}$ and $\mathrm{C} 3 \mathrm{~b} .^{23} \mathrm{C} 3 \mathrm{~b}$ inactivation by $\mathrm{CFI}$ is regulated by $\mathrm{CFH}$. CFH acts as a cofactor for CFI-mediated cleavage of $\mathrm{C} 3 \mathrm{~b}$ and also has decay accelerating activity against the alternative pathway C3 convertase, C3bBb. Membrane cofactor protein (or CD46) also acts as a cofactor for CFI-mediated cleavage of C3b by downregulating the complement cascade. ${ }^{24}$

Although it would be a remarkable coincidence if CFI is not the associated gene, in the absence of a proven causal variant, we cannot formally exclude PLA2G12A from consideration as the source of this association. Secreted PLA2G12A, expressed by the corneal epithelium, could be involved in the normal antibacterial activity in tears and wound healing. ${ }^{25}$ PLA2G12A has been shown to have bactericidal activity against the Gram-negative bacterium Escherichia coli and Helicobacter pylori in vitro. ${ }^{26}$ PLA2G12A might also participate in helper T-cell immune response by the release of immediate second signals and generation of downstream eicosanoids. ${ }^{27}$

With this result we have found two SNPs and their combined haplotype that achieve genome-wide significance. ${ }^{19,20}$ It is technically possible that the two intergenic SNPs could form a functional haplotype. However, a more likely explanation is that these SNPs tag an undiscovered, biologically relevant, structural variant. The next step will be to more comprehensively evaluate this region with the aim of uncovering this variation.

\section{Acknowledgements}

Funding was provided by the National Institutes of Health grant EY11309; the Foundation Fighting Blindness; the Massachusetts Lions Research Fund; Research to Prevent Blindness; Macular Degeneration Research Fund of the Ophthalmic Epidemiology and Genetics Service, the New England Eye Center, Tufts Medical Center; Center for Inherited Disease Research; and the Broad Institute Center for Genotyping and Analysis (through grant U54 RR020278 from the National Center for Research Resources). We thank AREDS participants and investigators and the EMMES Corporation for their work on the AREDS Genetic Repository. We also thank Daniel Mirel, Brian Galloway (project management); Robb Onofrio, Rob Borowski, Kat Irzene, Tony Rachupka (genotyping/sequencing), David Turner, Meg Parker (sample management); and Chris Cotsapas (bioinformatics).

\section{References}

1 Fisher SA, Abecasis GR, Yashar BM et al: Meta-analysis of genome scans of age-related macular degeneration. Hum Mol Genet 2005; 14: $2257-2264$

2 Klein RJ, Zeiss C, Chew EY et al: Complement factor $\mathrm{H}$ polymorphism in age-related macular degeneration. Science 2005; 308: 385-389.

3 Haines JL, Hauser MA, Schmidt S et al: Complement factor $\mathrm{H}$ variant increases the risk of age-related macular degeneration. Science 2005; 308: 419-421.

4 Edwards AO, Ritter III R, Abel KJ et al: Complement factor $\mathrm{H}$ polymorphism and age-related macular degeneration. Science 2005; 308: $421-424$.

5 Hageman GS, Anderson DH, Johnson LV et al: A common haplotype in the complement regulatory gene factor $\mathrm{H}$ (HF1/ $\mathrm{CFH})$ predisposes individuals to age-related macular degeneration. Proc Natl Acad Sci USA 2005; 102: 7227-7232.

6 Rivera A, Fisher SA, Fritsche LG et al: Hypothetical LOC387715 is a second major susceptibility gene for age-related macular degeneration, contributing independently of complement factor $\mathrm{H}$ to disease risk. Hum Mol Genet 2005; 14: 3227-3236. 
7 Gold B, Merriam JE, Zernant J et al: Variation in factor B (BF) and complement component 2 (C2) genes is associated with age-related macular degeneration. Nat Genet 2006; 38: $458-462$.

8 Maller J, George S, Purcell S et al: Common variation in three genes, including a novel non-coding variant in CFH, dramatically influences risk of age-related macular degeneration. Nat Genet 2006; 38: 1055 - 1059 .

9 Maller JB, Fagerness JA, Reynolds RC, Neale BM, Daly MJ, Seddon JM: Variation in complement factor 3 is associated with risk of age-related macular degeneration. Nat Genet 2007; 39: $1200-1201$.

10 Diabetes Genetics Initiative of Broad Institute of Harvard and MIT, Lund University, and Novartis Institutes of BioMedical Research. et al: Genome-wide association analysis identifies loci for type 2 diabetes and triglyceride levels. Science 2007; 316: $1331-1336$.

11 Easton DF, Pooley KA, Dunning AM et al: Genome-wide association study identifies novel breast cancer susceptibility loci. Nature 2007; 447: 1087-1093.

12 Samani NJ, Erdmann J, Hall AS et al: Genomewide association analysis of coronary artery disease. $N$ Engl J Med 2007; 357: $443-453$.

13 Seddon J, Sobrin L: Epidemiology of age-related macular degeneration; In: Albert DM, Miller J (eds): The Principles and Practice of Ophthalmology, 3rd edn. W.B. Saunders: Philadelphia, 2007, pp 413-422.

14 Seddon JM, Sharma S, Adelman R: Evaluation of the clinical age-related maculopathy staging system. Ophthalmol 2006; 113: $260-266$.

15 Wiltshire S, de Bakker PI, Daly MJ: The value of gene-based selection of tag SNPs in genome-wide association studies. Eur J Hum Genet 2006; 14: 1209-1214.

16 Barrett JC, Fry B, Maller J, Daly MJ: Haploview: analysis and visualization of LD and haplotype maps. Bioinformatics 2005; 21: $263-265$
17 Purcell S, Neale B, Todd-Brown K et al: PLINK: a tool set for wholegenome association and population-based linkage analyses. Am J Hum Genet 2007; 81: 559-575.

18 Sullivan PF, Purcell S: Analyzing genome-wide association study data: a tutorial using PLINK; In: Neale BM, Ferreira MAR, Medland SE, Posthuma D (eds): Statistical Genetics: Gene Mapping Through Linkage and Association. Taylor and Table Francis: London, 2007, pp 355-394.

19 Dudbridge F, Gusnanto A: Estimation of significance thresholds for genomewide association scans. Genet Epidemiol 2008; 32: 227-234.

20 Pe'er I, Yelensky R, Altshuler D, Daly MJ: Estimation of the multiple testing burden for genomewide association studies of nearly all common variants. Genet Epidemiol 2008; 32: 381-385.

21 Kwan JSH, Purcell S, Sham PC: Introduction to biometrical genetics; In: Neale BM, Ferreira MAR, Medland SE, Posthuma D (eds): Statistical Genetics: Gene Mapping Through Linkage and Association. Taylor and Table Francis: London, 2007, pp 355-394.

22 Vyse TJ, Bates GP, Walport MJ, Morley BJ: The organization of the human complement factor I gene $(I F)$ : a member of the serine protease gene family. Genomics 1994; 24: 90-98.

23 Catterall CF, Lyons A, Sim RB, Day AJ, Harris TJ: Characterization of primary amino acid sequence of human complement control protein factor I from an analysis of cDNA clones. Biochem J 1987; 242: 849-856.

24 Jha P, Bora PS, Bora NS: The role of complement system in ocular diseases including uveitis and macular degeneration. Mol Immunol 2007; 44: 3901-3908.

25 Landreville S, Coulombe S, Carrier $\mathrm{P}$ et al: Expression of phospholipases A2 and $\mathrm{C}$ in human corneal epithelial cells. Invest Ophthalmol Vis Sci 2004; 45: 3997-4003.

26 Huhtinen HT, Grönroos JO, Grönroos JM et al: Antibacterial effects of human group IIA and group XIIA phospholipase A2 against Helicobacter pylori in vitro. APMIS 2006; 114: 127-130.

27 Ho IC, Arm JP, Bingham III CO, Choi A, Austen KF, Glimcher LH: A novel group of phospholipase A2s preferentially expressed in type 2 helper T cells. J Biol Chem 2001; 276: 18321-18326.

Supplementary information accompanies the paper on European Journal of Human Genetics website (http://www.nature.com/ejhg) 